\title{
Identification of rare-earth minerals associated to K-feldspar: Capacsaya project in Peru
}

\author{
$J^{\text {J. Ochoa }}{ }^{1} \cdot$ E. Monteblanco $^{2} \cdot$ L. Cerpa $^{3} \cdot$ A. Gutarra-Espinoza $^{1} \cdot$ L. Avilés-Félix ${ }^{4}$
}

Received: 6 May 2021 / Accepted: 3 November 2021

Published online: 11 December 2021

(c) The Author(s) 2021 OPEN

\begin{abstract}
A recently discovered the rare-earth-rich site in Capacsaya, located at $123 \mathrm{~km}$ northwest of Cusco, at the south of Peru, contains significant quantities of light and heavy rare-earth elements such as neodymium, lanthanum, cerium, europium, and yttrium. This work reports the identification of rare-earth elements and their associated minerals using scanning electron microscopy, energy-dispersive X-ray spectroscopy and X-ray diffraction analyses. Five (5) samples extracted from different locations at the Capacsaya site were characterized and identified K-feldspar as the mineral associated with the rare-earth elements in a representative sample with a high concentration of lanthanum and cerium. The results showed rare-earth elements contained within the mineral phase monazite, being cerium the dominant element in the phase $(\mathrm{La}, \mathrm{Ce}, \mathrm{Nd}) \mathrm{PO}_{4}$. Finally, through the electrostatic separation process we demonstrate that it was possible to achieve an efficient separation of the K-feldspar phase in the particle size range $75-150 \mu \mathrm{m}$.
\end{abstract}

Keywords Rare-earth minerals · K-feldspar · Electrostatic separation

\section{Introduction}

The wide variety of technological applications of rare earths elements (REE) explain its economic growth and political value [1]. Some industrial applications are related to the petroleum refining processes $(\mathrm{Lu})$, diesel engines (Ce) [2], biofuels (La, Ce) [3], ultrafast opto-spintronic memories (Tb, Gd) [4,5], fabrication of high temperature superconductors $(\mathrm{Y}, \mathrm{Nd}, \mathrm{Ce})[6,7]$, luminescence for telecommunications (La) $[8,9]$, nuclear reactors ( $\mathrm{Sm}, \mathrm{Eu}$, $\mathrm{Gd})$, fabrication of screens ( $\mathrm{Y}, \mathrm{Eu})$, permanent magnets $(\mathrm{Nd}, \mathrm{Ce}, \mathrm{Pr})[10,11]$ and among many other applications
[12-15]. Only in medicine, in specific applications such as the treatment of various types of cancer, the improvement of magnetic resonance imaging, the creation of new lasers and surgical instruments are involved different rare earth elements: $\mathrm{Y}, \mathrm{Nd}, \mathrm{Tb}, \mathrm{Gd}, \mathrm{Tm}$, and Ho. REE are only found in mineral deposits in the form of minerals such as oxides, phosphates or silicates, and additional physicaland chemical-based techniques separation are required for the obtention of REE as pure elements or as oxides. After its discovery, more than 200 years ago [15], immediately faced the problem of separating one element from another, representing a great challenge for the industrial

\footnotetext{
Supplementary Information The online version contains supplementary material available at https://doi.org/10.1007/s42452-021-04868y.

L. Avilés-Félix, lavilesf@cab.cnea.gov.ar; A. Gutarra-Espinoza, agutarra@uni.edu.pe | 'Laboratorio de Materiales Nanoestructurados, Facultad de Ciencias, Universidad Nacional de Ingeniera, Av. Túpac Amaru 210, Rimac, Lima, Peru. ${ }^{2}$ CEA-Service de Physique de I'Etat Condensé, Centre d'Etudes de Saclay, 91191 Gif-sur-Yvette, France. ${ }^{3}$ Instituto Geológico, Minero y Metalúrgico. INGEMMET, Avenida Canada 1470, San Borja, Lima, Peru. ${ }^{4}$ Comisión Nacional de Energía Atómica (CNEA), Consejo Nacional de Investigaciones Científicas y Técnicas (CONICET), Av. Bustillo 9500, San Carlos de Bariloche, R8402AGP Rio Negro, Argentina.
} 
and scientific community. Several physical techniques including gravity [16-19], flotation [20-23], magnetic [24, 25], and electrostatic [26-28] separation have been used during the last years for the beneficiation of REE. In a more global context and for a long time, China has accounted for more than $85 \%$ of the global rare-earth mining and production [14] and the $50 \%$ of reserves worldwide. Apart from China, only the USA, Australia, and Myanmar are the three other countries that mine most of the rare-earth every year. On the other hand, only Brazil from South America is considered as one of the top 10 countries for rare-earth metal production with a deposit of rare-earth deposit discovered in 2012 at the Salobo copper-mine project at Carajas in Para state. In this context, in 2015, it was announced a recently discovered rare-earth-rich site in Capacsaya, located at $123 \mathrm{~km}$ northwest of Cusco, at the south of Peru [29] (Fig. 1). Preliminary geological studies determined that the Capacsaya Project holds the highest rare earth ranges in the country, being the total rare-earth oxide values to a maximum of $1.2 \%$ and the light rare earth values go up to a maximum of $3 \%$ [30].

$72^{\circ} \mathrm{W}$

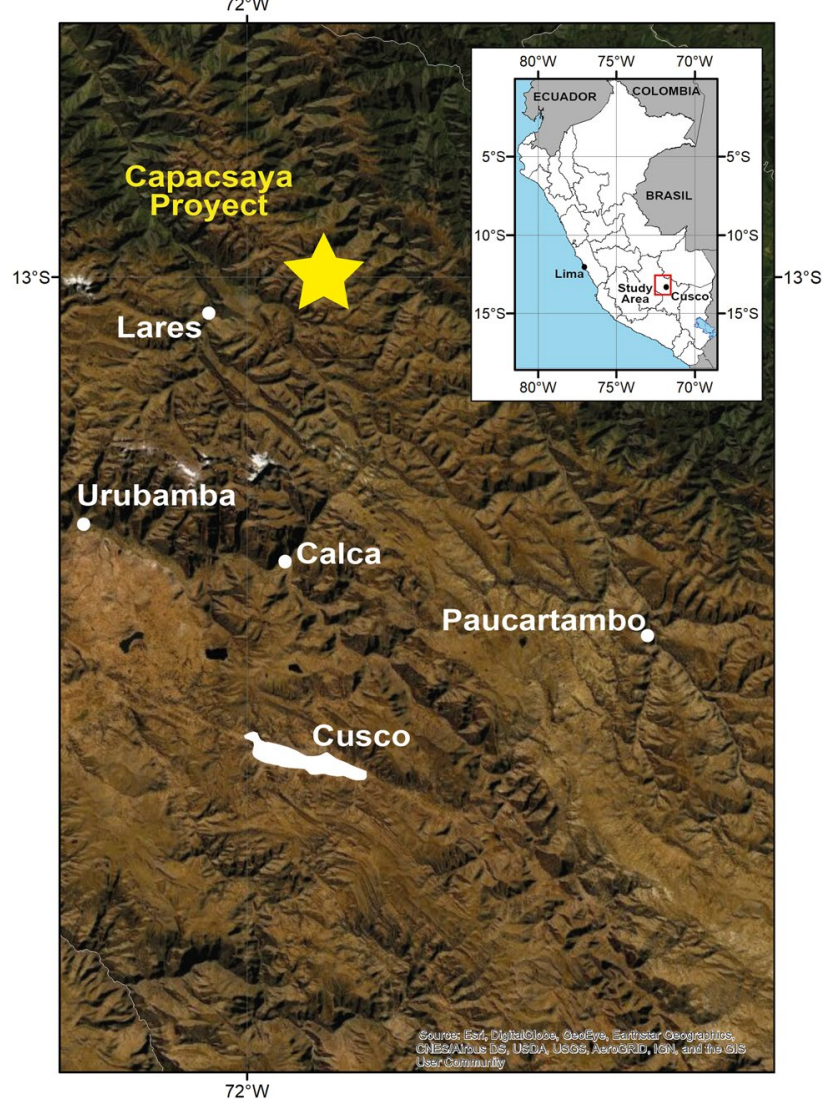

Fig. 1 Illustration of the location of Capacsaya site at northwest of Cusco (yellow star). Inset: Map of Peru indicating the coordinates in which Capacsaya site is located (red square)
In this study, the results of the characterization, including the identification and separation of rare-earth minerals of 5 samples extracted from different locations at the Capacsaya site in Cusco were reported. For the identification of the mineral phases, scanning electron microscopy (SEM), electron dispersive X-ray (EDEX) spectrometry and inductively coupling mass spectrometry (ICP-MS). For the separation of the mineral phase containing the rare-earth element a high voltage electrostatic separator was used. The versatility of the high voltage-assisted particle separation is evidenced for the different industrial applications that posses such as the separating stems and leaves in the food industry or the recycling of printed electronic circuits containing copper [31-33], among others. Over the years researchers have investigated the electrical separation processes $[34,35]$ focusing on optimizing the process through computational methods or theoretical and experimental analyzes. In this study, the electrostatic separation was also used to concentrate the rare-earth indicator mineral (K-feldspar and monazite) obtained from the characterization techniques.

\section{Experimental details}

The specimens were examined with a SEM-EDS TESCAN model Vega, that was equiped with a detector XFlash 4010/LN2 SDD. Samples had a granulometry of less than $150 \mu \mathrm{m}$. Prior to the SEM analysis, a polished section (briquette) of the sample was selected and a low vacuum coating with graphite was performed to improve the conductivity of the samples. X-ray diffraction measurements (XRD) were also performed in a Bruker-D8 Advance diffractometer in the Bragg-Brentano set-up with $280 \mathrm{~mm}$ of primary and secondary radius, the $2 \theta$ angular range used was $6^{\circ}-70^{\circ}$. The linear PSD $2 \theta$ angular range and the FDS angle were $2.94^{\circ}$ and $0.34^{\circ}$, respectively. High electric field-assisted separation was performed with an electrostatic high-tension roll (HTR) separator developed by CARPCO, which consists of ionizing and a separator electrodes supplied with high voltage between 1 and $50 \mathrm{kV}$. The separator is assisted by an AC electric field to remove the particles that remained in the rotor after passing the high electric field region. All the samples were annealed at $60^{\circ} \mathrm{C}$ before the electrostatic separation process to avoid conductivity changes due to humidity. An infrared incandescent lamp was also used to heat the environment previous to the electrostatic separation process to reduce humidity in the chamber. The operating conditions of the HTR used during the separation of the rare-earth minerals are: voltage of the ionizing electrode $U=7 \mathrm{kV}$; angular velocity $w=280 \mathrm{rpm}$; vibration of the feeder (in arbitrary units) $V_{f}=34 . d_{1}=50 \mathrm{~mm}, \theta_{1}=60^{\circ}, \phi_{1}=60^{\circ}$ and $\phi_{2}=40^{\circ}$.

\section{SN Applied Sciences}


A schematics of the CARPCO HTR indicating the different parameters can be found in the Supplementary data file. The different parameters of the HTR that control the separation process, such as the angular velocity of the rotor, the diameter of the rotor, and DC voltage applied to the ionizing and separator electrode were optimized previous to the experiments.

\section{Results}

\subsection{Identification of elements with Inductively coupled plasma mass spectrometry}

Five representative samples extracted from different locations at the Capacsaya site were analyzed via Inductively coupled plasma mass spectrometry (ICP-MS) to determine the concentration of rare-earth elements (in ppm). The pre-treatment process of the samples in the ICP-MS test was the following: samples were mechanically processed using a crusher, to obtain a particle size of approximately $150 \mu \mathrm{m}$ in a first stage. This material was then taken to a cracker and bring under a controlled pulverization until the particle size reached approximately $75 \mu \mathrm{m}$. Then the sample was attacked by four acids: hydrofluoric acid (HF), nitric acid $\left(\mathrm{HNO}_{3}\right)$, hydrochloric acid $(\mathrm{HCl})$ and perchloric acid $\left(\mathrm{HClO}_{4}\right)$. The test tubes with the prepared solution were measured on the ICP-MS Aligent-540 inductively coupled plasma mass spectrometry equipment. Table 1 presents the rare-earth element content for the different samples labeled as PE-0X. As seen from Table 1, PE-02 sample has the highest content of the different rare-earth elements compared to the others, at least one order of magnitude higher for the rare-earth elements $\mathrm{La}, \mathrm{Ce}, \mathrm{Pr}, \mathrm{Nd}$, $\mathrm{Sm}, \mathrm{Gd}$ and Dy. PE-04 sample also shows relatively high concentrations of heavy rare-earth elements like $\mathrm{Nd}, \mathrm{Gd}$, $\mathrm{Dy}, \mathrm{Ho}, \mathrm{Yb}$, and $\mathrm{Lu}$. In contrast, the lowest concentration of lanthanum and cerium was determined for sample PE-05. A similar concentration of $\mathrm{Er}, \mathrm{Tm}, \mathrm{Yb}$ and Lu were measured in all samples.

From the ICP-MS analyses of the samples, it was also possible to extract the different light elements within the $\mathrm{PE}-0 \mathrm{X}$ samples. The concentrations, given in percentage, of the elements $\mathrm{Al}, \mathrm{Ca}, \mathrm{Fe}, \mathrm{Mg}, \mathrm{K}, \mathrm{Na}, \mathrm{S}$, and $\mathrm{Ti}$ are listed in Table 2. Only the concentrations of $\mathrm{Fe}$ in $\mathrm{PE}-02$ and $\mathrm{Ca}$ in PE-04 are above $10 \%$. Compared to samples PE-01 and $\mathrm{PE}-03$, the contents of PE-02, PE-04, and PE-05 samples had larger quantities of $\mathrm{Ca}$ and $\mathrm{Fe}$. On the other hand, the presence of elements such as $\mathrm{K}, \mathrm{Na}$, $\mathrm{S}$, and $\mathrm{Ti}$ is significantly low in all the samples with concentrations below $5 \%$, being $\mathrm{Ti}$ the only element with a concentration less than $0.2 \%$ in all samples.

\subsection{Identification of rare-earth minerals with SEM-EDS}

Due to its highest content of light rare-earth elements, such as $\mathrm{La}, \mathrm{Ce}, \mathrm{Pr}, \mathrm{Nd}, \mathrm{Sm}$ and Eu, sample PE-02 was selected to identify additional elements and minerals using SEM and EDEX spectroscopy. Figure 2 shows the SEM

Table 1 Concentration of rare earth elements obtained with inductively coupled plasma mass spectrometry in samples extracted from 5 different locations in Capacsaya site in Cusco, Peru

\begin{tabular}{|c|c|c|c|c|c|c|c|c|c|c|c|c|c|c|}
\hline Sample & $\mathrm{La}$ & $\mathrm{Ce}$ & $\operatorname{Pr}$ & $\mathrm{Nd}$ & $\mathrm{Sm}$ & $\mathrm{Eu}$ & $\mathrm{Gd}$ & $\mathrm{Tb}$ & Dy & $\mathrm{Ho}$ & $\mathrm{Er}$ & $\mathrm{Tm}$ & $\mathrm{Yb}$ & Lu \\
\hline PE-01 & 111.8 & 155.3 & 12.15 & 36.8 & 6.4 & 0.79 & 5.83 & 0.98 & 6.29 & 1.25 & 3.64 & 0.56 & 3.67 & 0.56 \\
\hline PE-02 & 1489 & 2300 & 185.8 & 494.9 & 58.75 & 6.28 & 47.61 & 4.63 & 20.13 & 2.66 & 6.12 & 0.8 & 5.21 & 0.79 \\
\hline PE-03 & 123.6 & 183.9 & 16.13 & 48.9 & 7.64 & 1.04 & 6.28 & 0.89 & 5.44 & 1.0 & 2.84 & 0.43 & 2.88 & 0.42 \\
\hline PE-04 & 125.5 & 237.4 & 23.9 & 81.6 & 12.71 & 1.17 & 12.57 & 1.71 & 10.25 & 67.92 & 5.82 & 0.86 & 5.92 & 1.3 \\
\hline PE-05 & 96.5 & 183 & 17.87 & 59.6 & 9.58 & 1.01 & 9.63 & 1.24 & 7.45 & 1.47 & 4.32 & 0.63 & 4.41 & 0.81 \\
\hline
\end{tabular}

Quantities given are in ppm

Data in bold correspond to the samples with the highest (PE02) and with the lowest (PE-05) concentration of rare-earth elements

Table 2 Concentration of different elements obtained with Inductively coupled plasma in 5 different samples extracted from Capacsaya site

\begin{tabular}{lllllllll}
\hline Sample & Al & Ca & Fe & K & Mg & Na & S & Ti \\
\hline PE-01 & 6.04 & 1.38 & 1.78 & 0.19 & 0.66 & 4.75 & 1.02 & 0.12 \\
PE-02 & 2.42 & 9.63 & 12.38 & 1.44 & 3.56 & 0.13 & 2.11 & 0.08 \\
PE-03 & 6.91 & 0.25 & 1.6 & 3.67 & 0.13 & 3.22 & 0.09 & 0.15 \\
PE-04 & 0.47 & 13.5 & 6.71 & 0.05 & 6.91 & 0.2 & 0.02 & 0.07 \\
PE-05 & 2.51 & 7.82 & 7.67 & 1.21 & 7.81 & 0.42 & 0.02 & 0.16 \\
\hline
\end{tabular}

Quantities given are in percentage (\%) 

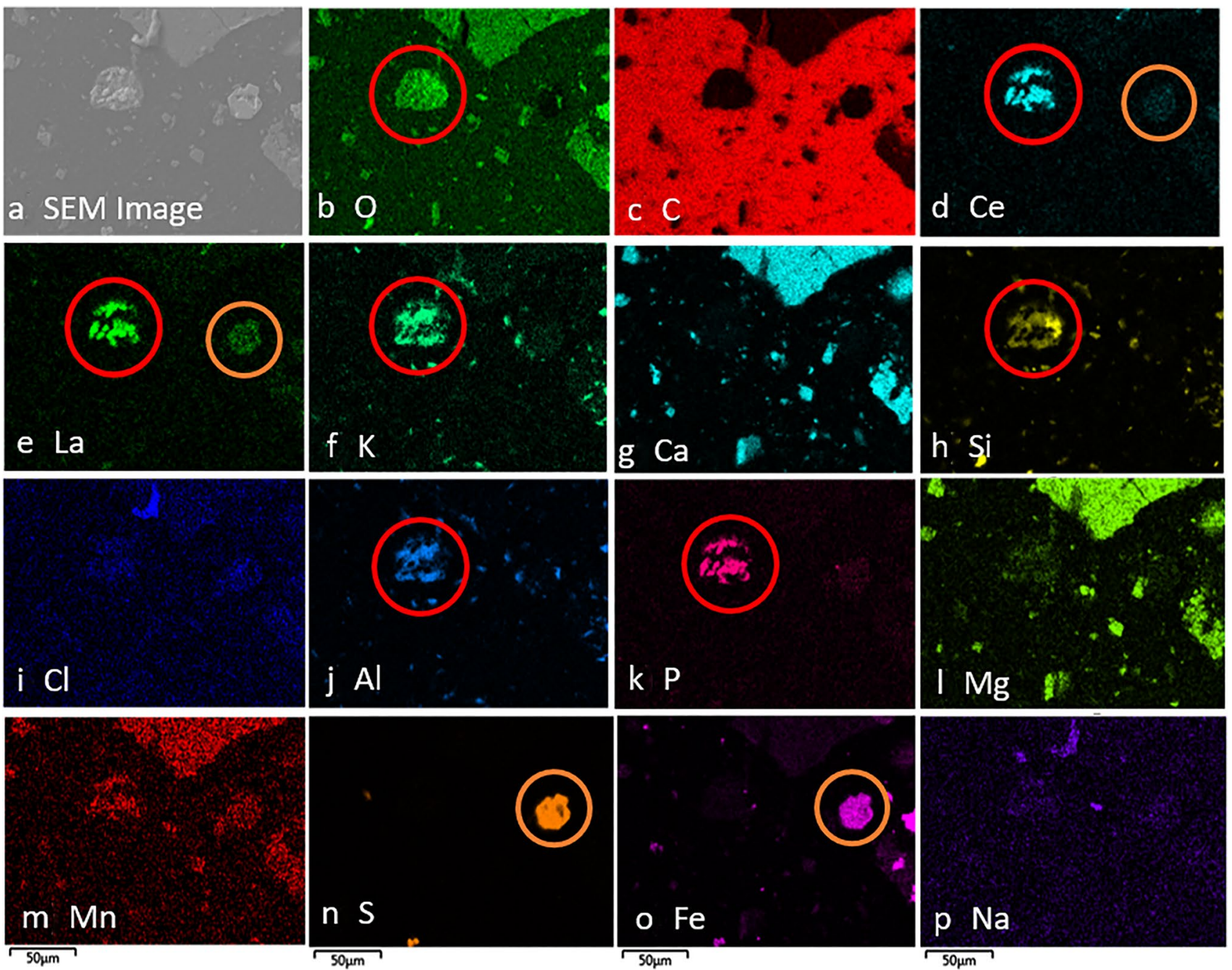

Fig. 2 a SEM image of a region of sample PE-02. b-p Element-specific energy dispersive X-ray spectroscopy images showing the presence of b O, c C, $\mathbf{d} \mathrm{Ce}, \mathbf{e ~ L a}, \mathbf{f ~ K}, \mathbf{g ~ C a}, \mathbf{h ~ S i , ~ i ~ C l , ~ j ~ A l , ~} \mathbf{k}$ P, I Mg, $\mathbf{m} \mathrm{Mn}, \mathbf{n} \mathrm{S}, \mathbf{o}$ Fe and $\mathbf{p} \mathrm{Na}$ in sample PE-02

image and the element-specific images of sample PE-02. The SEM image presented in Fig. 2a which corresponds to a region of $200 \mu \mathrm{m} \times 250 \mu \mathrm{m}$ allowed to identify two circularly-shaped features on a polished side of the sample. The EDS analysis on the scanned region indicate the presence of a wide range of elements such as $\mathrm{O}, \mathrm{C}, \mathrm{Ce}$, $\mathrm{La}, \mathrm{K}, \mathrm{Ca}, \mathrm{Si}, \mathrm{Cl}, \mathrm{Al}, \mathrm{P}, \mathrm{Mg}, \mathrm{Mn}, \mathrm{S}, \mathrm{Fe}$, and $\mathrm{Na}$ as also seen in Fig. 2b-p. It is important to notice that light rare-earth elements such as Ce and La only appeared in both central circularly-shape features of the image as indicated by red and orange circles in Fig. 2. High concentrations of oxygen, potassium, silicon, phosphorus, aluminum, highlighted with a red circle, allowed to identify the K-feldspar orthoclase $\left(\mathrm{KAISi}_{3} \mathrm{O}_{8}\right)$ as the mineral associated to the rare-earth minerals. According to Fig. $2 \mathrm{~d}, \mathrm{e}, \mathrm{n}$ and $\mathrm{o}$, lanthanum and cerium elements might also be associated to pyrite (FeS), as indicated by the orange circles.

\subsection{Identification of minerals with X-ray diffraction}

X-Ray analysis was used for the determination of the different minerals phases of the samples PE-OX. The presence of different minerals such as dolomite, quartz, K-feldspar, muscovite, hematite, pyrite, and calcite was determined in almost all samples. A detailed table with the concentrations of the different mineral phases in all the samples is shown in Table S1 in the Supplementary data file. Figure 3a shows the XRD pattern of a sample with a particle size between 75 and $150 \mu \mathrm{m}$, in which the different peaks corresponding to the phases dolomite, hematite, and quartz can be identified. Complementary to the XRD analysis, the elements present in sample PE-02 were identified from the EDS spectra (Fig. 3b) obtained from the region showed in Fig. 2a). EDS spectra of the samples shows the elemental composition of sample PE-02. EDS analyses of that area 
Fig. 3 a XRD pattern of sample PE-02 corresponding to a particles size between 75 and $150 \mu \mathrm{m}$. b Electron dispersive spectroscopy spectra obtained from a region of $200 \mu \mathrm{m} \times 250$ $\mu \mathrm{m}$ of sample PE-02
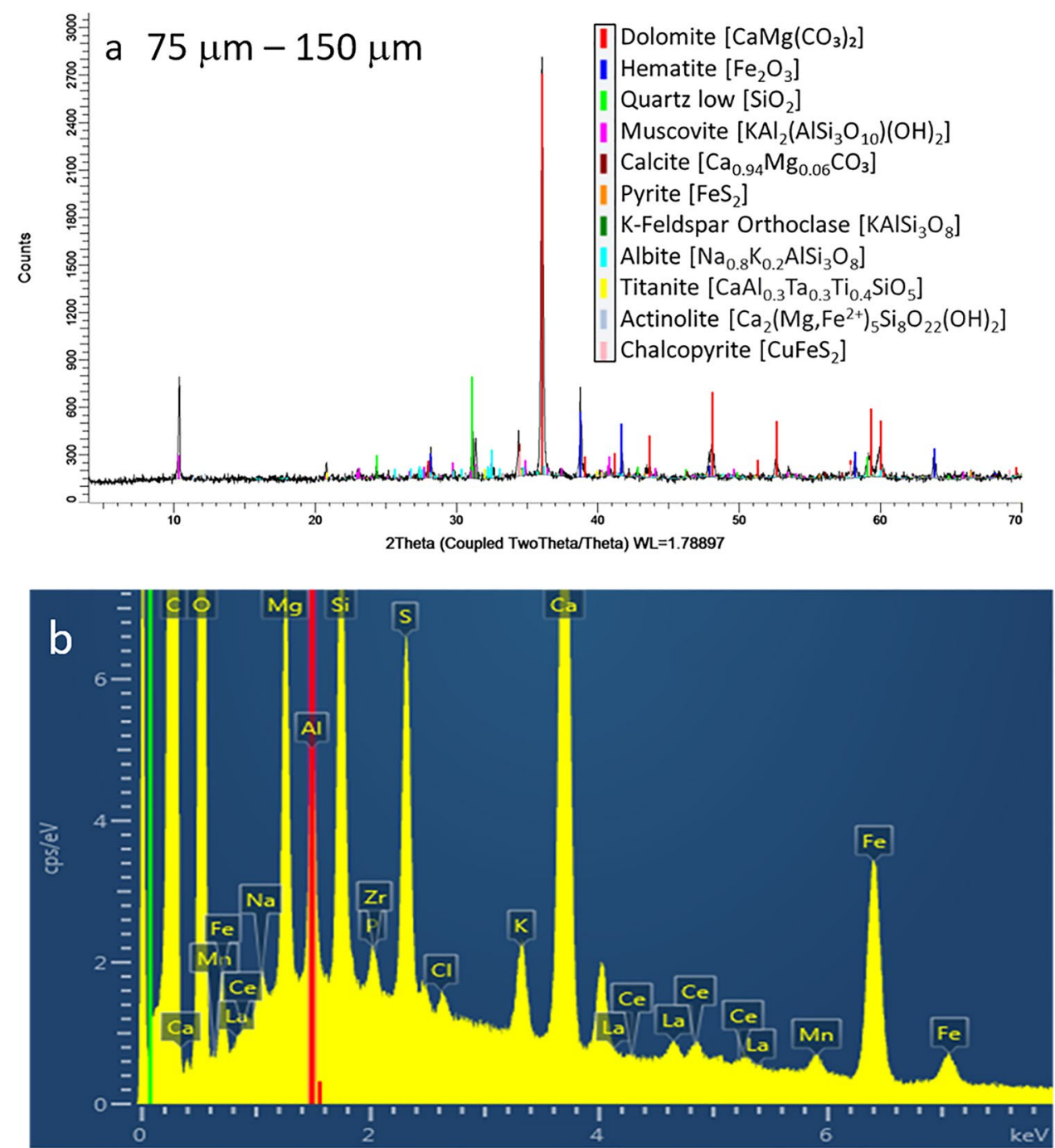

indicate that the concentration of the metallic elements (C, Mg, Si, Al, Ca, K) screens the signal of the La and Ce.

A third mapping of sample PE-02 in a smaller region of Fig. 3 (obtained from the zone highlighted with a red circle) not only allowed us to identify the presence of light rare-earths, but also the mineral associated with it. As can be seen from Fig. $4 a-f$, the SEM image of a $50 \mu \mathrm{m} \times 50 \mu \mathrm{m}$ region and the element-specific EDS mapping of a smaller area around $3 \mu \mathrm{m} \times 3 \mu \mathrm{m}$ confirmed the presence of elements such as lanthanum, cerium, neodymium, phosphorus, and oxygen. Calcium and aluminum in smaller quantities were also identified (not shown in Fig. 4).

EDS spectra shown in Fig. $4 \mathrm{~g}$ also detects the relatively high contents of $\mathrm{Ce}$, $\mathrm{La}$, and $\mathrm{Nd}$. The weight percentage obtained from the EDS analyses for the different elements extracted from Fig. $4 b-g$ are the following: $\mathrm{Ce}-29.1 \%, \mathrm{O}-28.7 \%$, La-24.8\%, P-14.0\%, and $\mathrm{Nd}-3.4 \%$. These values of weight percentage suggest that the mineral being observed in Fig. 4 contains relevant quantities of monazite. Therefore, assuming that the elements observed in the mappings of Fig. 4 form the mineral $(\mathrm{La}, \mathrm{Ce}, \mathrm{Nd})_{z} \mathrm{P}_{y} \mathrm{O}_{x}$ and the atomic mass of each element: $M^{O}=16, M^{P}=30.98, M^{C e}=140.12, M^{\text {La }}$ $=138.92$ and $M^{N d}=144.27$, it is possible to calculate the values of $x, y$ and $z$ obtaining $(\mathrm{La}, \mathrm{Ce}, \mathrm{Nd}) \mathrm{PO}_{4}$, which demonstrate the presence of monazite, one of the principal rare-earth minerals exploited in the mining industry. Due to cerium is the dominant element in this phase, the mineral corresponds to monazite-Ce. As was also mentioned in the previous section the presence of elements such as $\mathrm{Si}, \mathrm{Al}$, and $\mathrm{K}$ (as shown in Fig. 3f, j, h.) indicate that the monazite-Ce is associated with the K-feldspar $\left(\mathrm{KAISi}_{3} \mathrm{O}_{8}\right)$.

\subsection{Electrostatic separation of rare-earth minerals}

As was demonstrated in the previous section sample PE-02 contains rare earth elements associated with monazite, 
Fig. 4 a SEM image of a 50 $\mu \mathrm{m} \times 50 \mu \mathrm{m}$ region of sample PE-02. b Element mapping images for $\mathbf{b} \mathrm{Ce}, \mathbf{c ~ L a}, \mathbf{d ~ N d}$, e O and $\mathbf{f} P$ of the $P E-02$ sample in a $3 \mu \mathrm{m} \times 3 \mu \mathrm{m}$ region indicated by the yellow square in (a). $\mathbf{g}$ EDS spectra obteined from the $3 \mu \mathrm{m} \times 3 \mu \mathrm{m}$ region showed in Fig. $4 a$
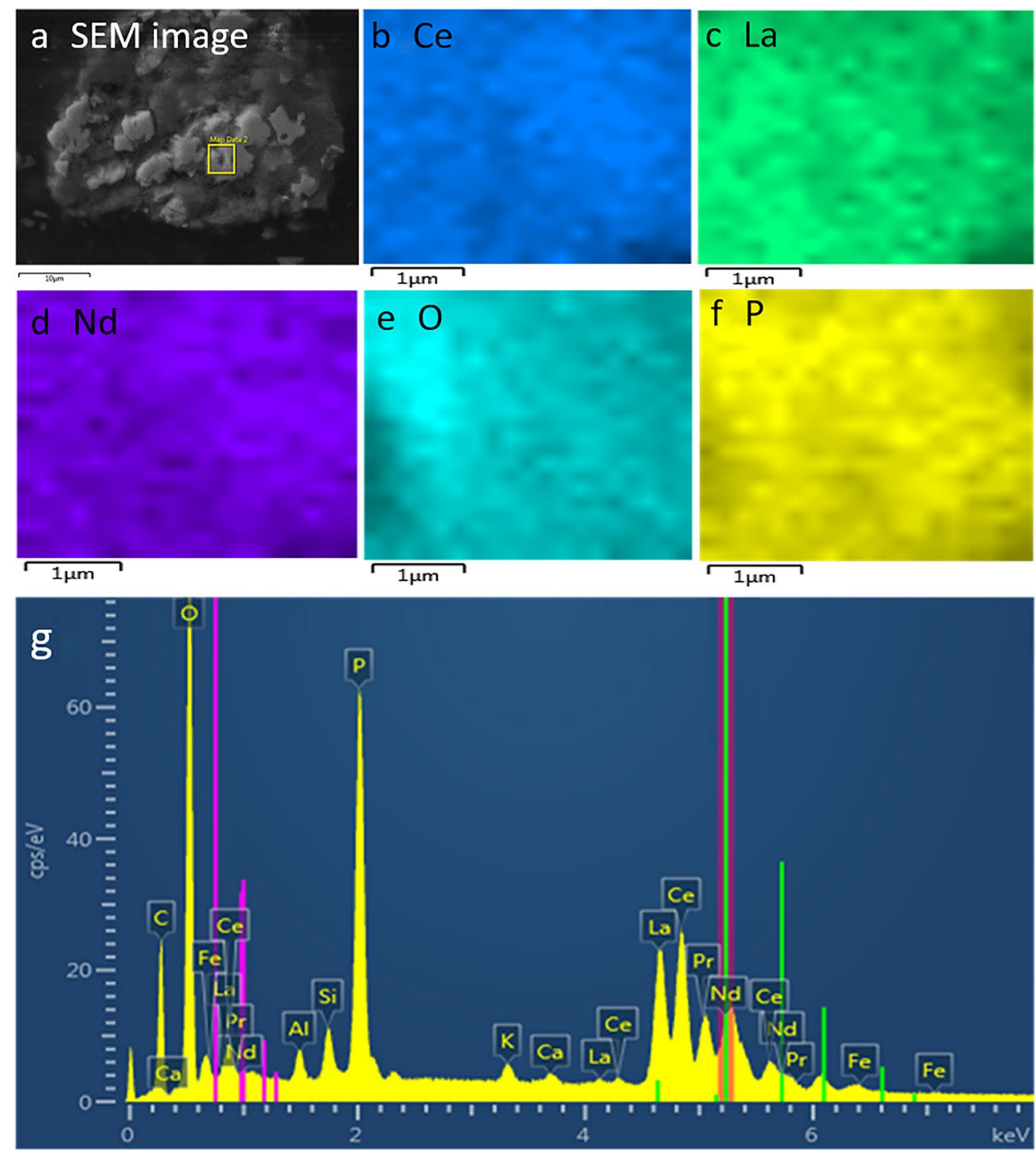

being cerium the dominant rare earth. Due to monazite-Ce is also associated to K-feldspar the electrostatic separation was attempted to increase the concentration of rare-earth minerals. To achieve this, samples PE-02 and PE-05 were chosen due to they contained the highest and the lowest concentration of REE, respectively. The conductivity of the minerals identified from ICP, SEM-EDS, and XRD analyses is well known and it is possible to classify them as conductive and non-conductive materials. Among the conductive phases present in $\mathrm{PE}-\mathrm{OX}$ samples, pyrite, hematite and chalcopyrite minerals were identified. On the other hand, among the non-conductive minerals dolomite, quartz, muscovite, calcite, actinolite, K-feldspar, plagioclase, titanite, and chlorite were identified [36]. Due to the capacity electrical separation is considerably small for fine particles $(<75 \mu \mathrm{m}$.), two group of samples were prepared according to the size: $<75 \mu \mathrm{m}-150 \mu \mathrm{m}>$ and $<150 \mu \mathrm{m}-250 \mu \mathrm{m}>$. The electrical behavior of the different minerals identified in the sample PE-02 before the separation process is presented in the third column of Table 3.

From all the minerals listed in Table 3, hematite (conductor) and dolomite (non-conductor) are the minerals with the highest concentrations for both particle size ranges. It is important to notice that the concentration of $\mathrm{K}$-feldspar (non-conductor), which is associated with the monazite-Ce is less than $3 \%$ before the separation process. After the separation process of the two range sizes, the conductor and non-conductor particles were separated and deposited into two containers labeled as conductor (C) and not-a-conductor (NC). Columns 4 and 5 Table 3 list the XRD results of the conductor, non-conductor fractions after the electric separation for the two different particle size of sample PE-02. The XRD spectra of the sample PE-02 before and after the separation process and for both particle sizes $<75 \mu \mathrm{m}-150 \mu \mathrm{m}>$ and $<150 \mu \mathrm{m}-250 \mu \mathrm{m}>$ can be found in section $\mathrm{S} 5$ of the Supplementary data file. After 
Table 3 Conductivity of the minerals found in sample PE-02 with XRD and concentration of the conductor and non-conductor fraction of sample PE-02 after electric separation

\begin{tabular}{|c|c|c|c|c|c|c|}
\hline Phase & Formula & Conduct. $^{a}$ & Part. size $(\mu \mathrm{m})$ & Initial $^{\mathrm{b}}(\%)$ & C fraction (\%) & NC fraction (\%) \\
\hline \multirow[t]{2}{*}{ Hematite } & \multirow[t]{2}{*}{$\mathrm{Fe}_{2} \mathrm{O}_{3}$} & \multirow[t]{2}{*}{ C } & $75-150$ & 16.1 & 30.2 & 14.2 \\
\hline & & & $150-250$ & 15.9 & 38.6 & 14.3 \\
\hline \multirow[t]{2}{*}{ Pyrite } & \multirow[t]{2}{*}{$\mathrm{FeS}_{2}$} & \multirow[t]{2}{*}{ C } & $75-150$ & 4.1 & 5.9 & 2.8 \\
\hline & & & $150-250$ & 1.7 & 4.2 & 3.1 \\
\hline \multirow[t]{2}{*}{ Chalcopyrite } & \multirow[t]{2}{*}{$\mathrm{CuFeS}_{2}$} & \multirow[t]{2}{*}{ C } & $75-150$ & 2.3 & 2.4 & 1.7 \\
\hline & & & $150-250$ & 0.8 & 1.2 & 1.0 \\
\hline \multirow[t]{2}{*}{ Dolomite } & \multirow[t]{2}{*}{$\mathrm{CaMg}\left(\mathrm{CO}_{3}\right)_{2}$} & \multirow[t]{2}{*}{ NC } & $75-150$ & 48.4 & 29.5 & 42.8 \\
\hline & & & $150-250$ & 46.2 & 25.0 & 40.9 \\
\hline \multirow[t]{2}{*}{ Muscovite } & \multirow[t]{2}{*}{$\mathrm{KAl}_{3} \mathrm{Si}_{3} \mathrm{O}_{10}(\mathrm{OH})_{1.8} \mathrm{~F}_{0.2}$} & \multirow[t]{2}{*}{ NC } & $75-150$ & 10.9 & 8.4 & 13.0 \\
\hline & & & $150-250$ & 12.1 & 10.6 & 10.4 \\
\hline \multirow[t]{2}{*}{ Quartz } & \multirow[t]{2}{*}{$\mathrm{SiO}_{2}$} & \multirow[t]{2}{*}{ NC } & $75-150$ & 8.5 & 7.8 & 6.9 \\
\hline & & & $150-250$ & 13.7 & 11.74 & 11.5 \\
\hline \multirow[t]{2}{*}{ Calcite } & \multirow[t]{2}{*}{$\mathrm{CaCO}_{3}$} & \multirow[t]{2}{*}{ NC } & $75-150$ & 4.1 & 3.4 & 5.7 \\
\hline & & & $150-250$ & 2.8 & 0.7 & 5.7 \\
\hline \multirow[t]{2}{*}{ Actinolite } & \multirow[t]{2}{*}{$\mathrm{Ca}_{2}\left(\mathrm{Mg} ; \mathrm{Fe}^{2+}\right) \mathrm{Si}_{8} \mathrm{O}_{22}(\mathrm{OH})_{22}$} & \multirow[t]{2}{*}{ NC } & $75-150$ & 2.2 & 2.5 & 2.3 \\
\hline & & & $150-250$ & 1.06 & 1.4 & 5.0 \\
\hline \multirow[t]{2}{*}{ K-Feldspar } & \multirow[t]{2}{*}{$\mathrm{KAISi}_{3} \mathrm{O}_{8}$} & \multirow[t]{2}{*}{$\mathrm{NC}$} & $75-150$ & 1.9 & 0.3 & 3.1 \\
\hline & & & $150-250$ & 2.5 & 1.1 & 2.3 \\
\hline \multirow[t]{2}{*}{ Plagioclase } & \multirow[t]{2}{*}{$(\mathrm{Na}, \mathrm{Ca})(\mathrm{Si}, \mathrm{Al})_{3} \mathrm{O}_{8}$} & \multirow[t]{2}{*}{ NC } & $75-150$ & 1.1 & 9.5 & 7.5 \\
\hline & & & $150-250$ & 3.0 & 3.6 & 4.4 \\
\hline \multirow[t]{2}{*}{ Titanite } & \multirow[t]{2}{*}{$\mathrm{CaTiSiO}_{5}$} & \multirow[t]{2}{*}{ NC } & $75-150$ & - & - & - \\
\hline & & & $150-250$ & 0.07 & 0.01 & 0.02 \\
\hline Chlorite & $\left(\mathrm{Mg}, \mathrm{Fe}^{2+}\right)_{5} \mathrm{Al}\left((\mathrm{OH})_{8} / \mathrm{AlSi}_{3} \mathrm{O}_{10}\right)$ & NC & $75-150$ & - & - & - \\
\hline & & & $150-250$ & 0.1 & 1.8 & 1.3 \\
\hline
\end{tabular}

The separation was performed for two particle sizes: $<75-150 \mu \mathrm{m}>$ and $<150-250 \mu \mathrm{m}>$

a Conductivity: $C$ conductor, NC not a conductor

${ }^{b}$ Concentration of minerals in the sample PE-02 previous to the electric separation process

the electrical separation of the minerals the remaining samples were analyzed using the XRD to determine the concentration of the constituent mineral of both conductor and non-conductor fractions. For the size range $<75 \mu \mathrm{m}-150 \mu \mathrm{m}>$ the separation of hematite, pyrite, and chalcopyrite was efficient, due to the conductor fraction increased with respect to the initial concentration. On the other hand, the non-conductor phases K-feldspar, calcite, muscovite, and dolomite were separated into the nonconductor zone as expected [37], according to the concentration shown in Table 3. Non-conductor minerals such as quartz, actinolite or plagioclase within the size range $<75 \mu \mathrm{m}-150 \mu \mathrm{m}>$, which present a higher concentration in the conductor fraction after the separation, could be associated to conductor phases. In contrast, for bigger particles of actinolite and plagioclase, $<150 \mu \mathrm{m}, 250 \mu \mathrm{m}>$, the higher concentrations were observed within the non-conductor fraction. After the separation, the concentration of actinolite is the most efficient for bigger particles, changing the content into the non-conductive zone to $5.0 \%$ with respect to $1.06 \%$ measured in the initial sample previous to the separation. It is known that particle size influences the separation behavior due to the surface charges of fine particles is higher compared with the surface charge of coarse particles, as was evidenced for the actinolite and plagioclase, however, this was not observed for the case of quartz in the electric separation of the samples in this study. On the other hand, it is important to highlight that the separation of the K-feldspar phase into the nonconductive zone of the separator was more efficient for smaller particles having $1.9 \%$ before the separation and $0.3 \%$ and $3.1 \%$ contained in the $C$ and NC fraction, respectively. The variation of the concentration of the mineral phases was also evaluated for sample PE-05. The concentration of the conductor and non-conductor fraction of the sample PE-05 before and after electric separation is shown in Table S2 of the Supplementary data file. In this sample the separation was also performed for two particle sizes: $<75-150 \mu \mathrm{m}>$ and $<150-250 \mu \mathrm{m}>$. In contrast to sample 

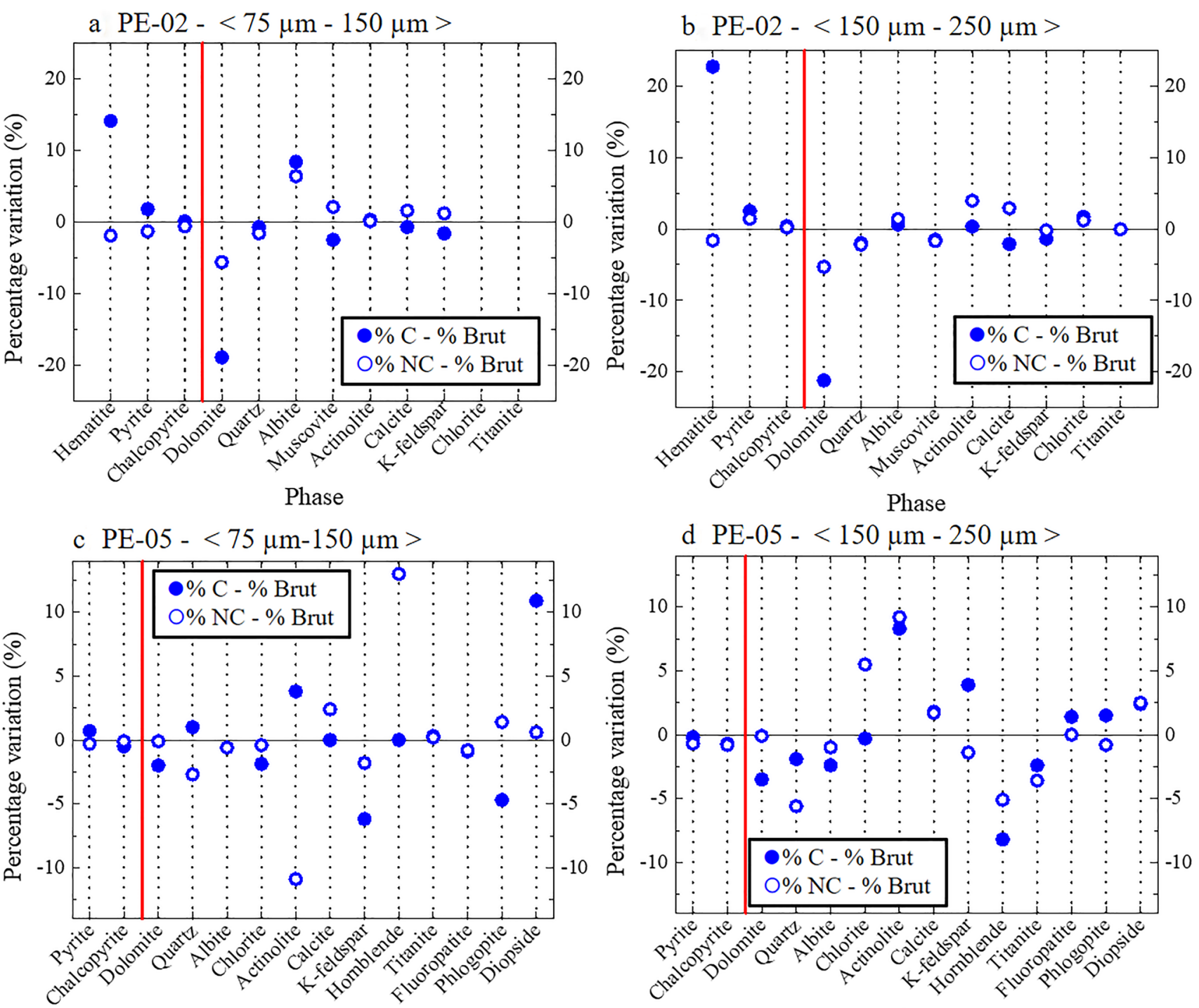

Phase

Phase

Fig. 5 Percentual difference between conductor and non-conductor relative concentration with respect to the initial relative concentration of the minerals found in samples PE-02 and PE-05 after electrostatic separation process.The percentage variation have been obtained for two different particle sizes: $<75-150 \mu \mathrm{m}>$ and $<150$

PE-02, K-feldspar separation was efficient only for a particle size range $<75-150 \mu \mathrm{m}>$.

Finally, to evaluate the efficiency of the electrostatic separation as a function of the mineral phases contained in samples PE-02 and PE-05 we plot in Fig. 5 the percentage variation between the concentration of the minerals in the conductor and non-conductor fraction after separation with respect to its concentration before the separation: according to \%C - \%Brut and \%NC - \%Brut. Filled symbols in Fig. 5 correspond to \%C - \%Brut and empty symbols to $\% \mathrm{NC}$ - \%Brut.

$250 \mu \mathrm{m}>$. Filled symbols correspond to $\% \mathrm{C}$ - \%Brut and empty symbols to \%NC - \%Brut. The red solid line separates the conductor (hematite, pyrite and chalcopyrite) from the non-conductor (dolomite, quartz or albite) mineral phases

Plots in Fig. 5 will allow us to identify an efficient separation across the different mineral phases for both particle size ranges. Filled circles located to the left of the red solid line with a positive percentage variation, indicate an efficient separation of the conductive mineral phase. On the other hand, empty circles (to the rigth of the red line) with a positive percentage variation indicate an efficient separation of the non-conductive mineral phases. Percentage variation obtained for pyrite, hematite, and chalcopyrite in sample PE-02 according to \%C - \%Brut (Fig. 5a, b) evidence an efficient separation of these phases for all particle sizes. However, this is not so 
evident after the separation of pyrite and chalcopyrite in sample PE-05 (Fig. 5c, d), in which the concentration of these phases in the conductor containers is similar to the concentration before the separation. It is also possible to identify, that in sample PE-02 the mineral phases albite, muscovite, actinolite, calcite, K-feldspar, chlorite, and titanite suffered an efficient separation towards the non-conductive containers during the electrostatic separation for smaller particle sizes (Fig. 5a). Similar percentage variation values for dolomite and hematite might suggest that these two phases are combined. In contrast, separation of the different phases in PE-05 is not as efficient compared with sample PE-02. Only hornblende, calcite, and diopside increased their concentration in the non-conductive container after the separation process for a particle size range $<75-150 \mu \mathrm{m}>$ (blue open circles in Fig. 5c).

\section{Conclusions}

5 samples extracted from different location in a recently discovered rare-earth site in Capacscaya, Cusco in the south of Peru were characterized in detail. Inductively coupled plasma mass spectrometry (ICP-MS) allowed to identify significant quantities of neodymium, lanthanum, cerium, europium and yttrium, in the samples. The identification of the elements performed with scanning electron microscopy and energy dispersive $\mathrm{X}$-ray (EDS) spectrometry also allowed us to determine the $\mathrm{K}$-feldspar orthoclase $\left(\mathrm{KAISiO}_{3}\right)$ as one of the mineral phases associated to the rare-earth minerals. On the other hand, from the EDS spectra, it was also possible to identify that the rare-earth elements is contained within the mineral phase monazite, being cerium the dominant element in the phase $(\mathrm{La}, \mathrm{Ce}, \mathrm{Nd}) \mathrm{PO}_{4}$. Through the electrostatic separation process, it was possible to achieve an efficient separation of the K-feldspar phase in the particle size range 75-150 $\mu \mathrm{m}$. The results for the electrosatic separation indicated that rare-earth elements were with monazite-Ce and $\mathrm{K}$-feldspar as indicator minerals before the complementary refining processes required during the extraction and production of rare-earth oxide products of greater purity. Further studies need to be performed in order to determine a detailed mapping of zones within the Capacsaya site with the highest concentration of rare-earth. The findings from this study allow us considering the Capacsaya site as a promising deposit found in the region in recent years.

Acknowledgements This research has received funding from the Programa Nacional de Innovación para la Competitividad y Productividad, Innóvate Perú, research project INNOVATE C128-PNICPPIAP-2014 and partially supported by the project INNOVATE C389PNICP-PIBA-2014 of the Production Ministry of Peru. The authors would like to thank V. Quinde and J. Pajuelo for their very valuable technical support and Elizabeth Carrera, José Díaz and Clemente Luyo for the SEM images.

\section{Declaration}

Conflict of interest The authors declare that they have no conflict of interest.

Open Access This article is licensed under a Creative Commons Attribution 4.0 International License, which permits use, sharing, adaptation, distribution and reproduction in any medium or format, as long as you give appropriate credit to the original author(s) and the source, provide a link to the Creative Commons licence, and indicate if changes were made. The images or other third party material in this article are included in the article's Creative Commons licence, unless indicated otherwise in a credit line to the material. If material is not included in the article's Creative Commons licence and your intended use is not permitted by statutory regulation or exceeds the permitted use, you will need to obtain permission directly from the copyright holder. To view a copy of this licence, visit http://creativecommons. org/licenses/by/4.0/.

\section{References}

1. Julie MK (2015) A historical geography of rare earth elements: from discovery to the atomic age. Extr Ind Soc 2(3):572-580

2. Dale JG, Cox SS, Vance ME, Marr LC, Hochella MF (2017) Transformation of cerium oxide nanoparticles from a diesel fuel additive during combustion in a diesel engine. Environ Sci Technol 51(4):1973-1980

3. NguyenLe-Phuc TV, Tran TT, Phan PT, Ngo QLM, Ha TN, Luong TH, Tran TT (2021) High-efficient production of biofuels using spent fluid catalytic cracking (FCC) catalysts and high acid value waste cooking oils. Renew Energy 168:57-63

4. Avilés-Félix L, Olivier A, Li G, Davies CS, Álvaro Gómez L, RubioRoy M, Auffret S, Kirilyuk A, Kimel AV, Rasing T, Buda-Prejbeanu LD, Sousa RC, Dieny B, Prejbeanu IL (2020) Single-shot alloptical switching of magnetization in $\mathrm{Tb} / \mathrm{Co}$ multilayer-based electrodes. Sci Rep 10(1):5211

5. Hadri MSE, Hehn M, Malinowski G, Mangin S (2017) Materials and devices for all-optical helicity-dependent switching. J Phys D Appl Phys 50(13):133002

6. Klepikova AS, Charikova TB, Popov MR, Stepanova EA, Ivanov AA (2021) Magnetic susceptibility anisotropy of electron overdoped high temperature superconductor $\mathrm{Nd}_{2-x} \mathrm{Ce}_{x} \mathrm{CuO}_{4}$. J Phys Chem Solids 148:109770

7. Mendes D, Sousa D, Cerdeira AC, Pereira LCJ, Marques A, Murta-Pina J, Pronto A, Ferreira I (2021) Low-cost and highperformance 3D printed YBCO superconductors. Ceram Int 47(1):381-387

8. Bünzli J-CG, Eliseeva SV (2010) Lanthanide NIR luminescence for telecommunications, bioanalyses and solar energy conversion. J Rare Earths 28(6):824-842

9. Ruby P, Pandey OP, Dhoble SJ (2021) Review on the synthesis, structural and photo-physical properties of $\mathrm{Gd}_{2} \mathrm{O}_{3}$ phosphors for various luminescent applications. Opt Laser Technol 135:106663

10. Luo S, Yaojun L, Zou Y, Zhong S, Yue W, Yang M (2021) Effect of low melting point powder doping on the properties and microstructure of sintered NdFeB magnets. J Magn Magn Mater 523:167620

11. Zhou T, Qu P, Pan W, Liu R, Li M, Sajjad Ur R, Zhenchen Z, Guoqiang X (2021) Sintered NdFeB magnets with Tb-Dy 
double-layer core/shell structure were fabricated by double alloy method and grain boundary diffusion. J Alloys Compd 856:158191

12. Hizhnyakov V, Boltrushko V, Kaasik H, Orlovskii Y (2021) Rare earth ions doped mixed crystals for fast quantum computers with optical frequency qubits. Opt Commun 485:126693

13. Jha AR (2014) Rare earth materials: properties and applications. Taylor and Francis group, London

14. Haque N, Hughes A, Lim S, Vernon C (2014) Rare earth elements: overview of mining, mineralogy, uses, sustainability and environmental impact. Resources 3(4):614-635

15. Gupta CK, Krishnamurthy N (1992) Extractive metallurgy of rare earths. Int Mater Rev 37(1):197-248

16. Jordens A, Sheridan RS, Rowson NA, Waters KE (2014) Processing a rare earth mineral deposit using gravity and magnetic separation. Miner Eng 62:9-18 (SI: Physical Separation)

17. Abaka-Wood GB, Quast K, Zanin M, Addai-Mensah J, Skinner W (2019) A study of the feasibility of upgrading rare earth elements minerals from iron-oxide-silicate rich tailings using Knelson concentrator and Wilfley shaking table. Powder Technol 344:897-913

18. Dehaine Q, Filippov LO, Joussemet R (2017) Rare earths (La, $\mathrm{Ce}, \mathrm{Nd}$ ) and rare metals ( $\mathrm{Sn}, \mathrm{Nb}, \mathrm{W}$ ) as by-products of kaolin production-part 2: gravity processing of micaceous residues. Miner Eng 100:200-210

19. Mariona C, Grammatikopoulos T, Rudinsky S, Langlois R, Williams $\mathrm{H}$, Chu P, Awais M, Gauvin R, Rowson NA, Waters KE (2018) A mineralogical investigation into the pre-concentration of the Nechalacho deposit by gravity separation. Miner Eng 121:1-13

20. Jordens A, Marion C, Grammatikopoulos T, Hart B, Waters KE (2016) Beneficiation of the Nechalacho rare earth deposit: flotation response using benzohydroxamic acid. Miner Eng 99:158-169

21. Espiritu ER (2018) Benefication of rare earth minerals from Niobec Ore: froth flotation. McGill University, Montreal

22. Abaka-Wood GB, Zanin M, Addai-Mensah J, Skinner W (2018) Recovery of rare earth elements minerals from iron oxide-silicate rich tailings-part 2: froth flotation separation. Miner Eng 142:105888

23. Geneyton A, Filippov LO, Heinig T, Buaron N, Menad NE (2021) Towards the efficient flotation of monazite from silicate-rich tailings with fatty acids collectors using a lanthanum salt as a selective phosphate activator. Miner Eng 160:106704

24. André FP, Miceli H, Moura LC, Neumann R, Tavares LM (2019) Upgrading a manufactured fine aggregate for use in concrete using dry rare-earth magnetic separation. Miner Eng 143:105942

25. Abaka-Wood GB, Zanin M, Addai-Mensah J, Skinner W (2019) Recovery of rare earth elements minerals from iron oxidesilicate rich tailings part 1: magnetic separation. Miner Eng 136:50-61
26. Harjanto S, Virdhian S, Afrilinda E (2013) Characterization of Indonesia rare-earth minerals and their potential processing techniques. In: Proceedings of the 52nd conference of metallurgists, pp 99-108

27. Archana K, Rekha P, Manis Kumar Jha, J. Rajesh Kumar, and Jin Young Lee. Process development to recover rare earth metals from monazite mineral: A J, Kumar JR, Lee JY (2015) Process development to recover rare earth metals from monazite mineral: a review. Miner Eng 79:102-115

28. Moghise M, Pourrahim M, Rezai B, Gharabaghi M (2016) Concentration and recycling of rare earth elements (rees) from iron mine waste using a combination of physical separation methods. J Min Environ 7(2):195-203

29. Jamasmie $C$ (2015) Peruvian rare earth discovery richer than initially thought. Mining.com. https://www.mining.com/peruv ian-rare-earth-discovery-richer-than-initially-thought-97023/

30. Cruz M, Mamani M, Rodriguez R (2015) Geochemical characteristic of Capacsaya deposit and relationship with LREE concentration. Mining.com, 2015. Cusco-Peru. Pro Explo

31. Li J, Hongzhou L, Zhenming X, Zhou Y (2008) Critical rotational speed model of the rotating roll electrode in corona electrostatic separation for recycling waste printed circuit boards. J Hazard Mater 154(1):331-336

32. Jiang W, Li J, Zhenming $X$ (2009) An improved model for computing the trajectories of conductive particles in roll-type electrostatic separator for recycling metals from weee. J Hazard Mater 167(1):489-493

33. Richard G, Salama AR, Medles K, Lubat C, Touhami S, Dascalescu $L$ (2017) Experimental and numerical study of the electrostatic separation of two types of copper wires from electric cable wastes. IEEE Trans Ind Appl 53(4):3960-3969

34. Tripathy SK, Ramamurthy Y, Kumar CR (2010) Modeling of hightension roll separator for separation of titanium bearing minerals. Powder Technol 201(2):181-186

35. Maammar M, Medles K, Aksa W, Touhami S, Dascalescu L, Zeghloul T (2019) Validation of the numerical model of particle trajectories in a multifunctional electrostatic separator. In: 2019 IEEE industry applications society annual meeting, pp 1-4

36. Gent M, Menendez M, Toraño J, Torno S (2011) A review of indicator minerals and sample processing methods for geochemical exploration. J Geochem Explor 110(2):47-60

37. Han KN, Fuerstenau MC (2005) Principles of mineral processing. Society for Mining, Metallurgy, and Exploration Inc, Englewood

Publisher's Note Springer Nature remains neutral with regard to jurisdictional claims in published maps and institutional affiliations. 